\title{
RBEP
}

\section{Programa Nacional do Livro Didático (PNLD) - Acervos Complementares: vivência das estratégias de leitura na alfabetização}

Rielda Karyna de Albuquerque

Magna Silva Cruz

http://dx.doi.org/10.1590/S2176-6681/338012913

\section{Resumo}

Analisa o uso das obras do Programa Nacional do Livro Didático (PNLD) - Acervos Complementares e busca promover a compreensão leitora por meio da vivência de estratégias de leitura. Duas professoras, uma do $1^{\circ} \mathrm{e}$ outra do $2^{\circ}$ ano do ensino fundamental, participaram da pesquisa. Como procedimentos metodológicos, foram utilizados: análise documental do material oficial do PNLD - Acervos Complementares; entrevista com as professoras; e observação de aulas. Focaram-se as práticas de leitura por meio do uso dos materiais complementares. Os resultados apontam que as professoras promoveram situações de vivência de estratégias de leitura a fim de desenvolver habilidades de compreensão de textos, apesar de as atividades não terem sido devidamente planejadas.

Palavras-chave: PNLD - acervos complementares; estratégias de leitura; compreensão leitora; recursos didáticos; alfabetização. 


\section{Abstract \\ The National Program of Textbook (PNLD) - Complementary Collections: experience of reading strategies in literacy}

This paper analyzes the use of works of the National Textbook Program (PNLD) - Complementary Collections, and aims to promote the reading comprehension through the experience of reading strategies. Two teachers, teaching the first grade and the second grade of elementary school, participated in the research. The methodological procedures included documentary analysis of the official material of PNLD - Complementary Collections; interviews with the teachers and classroom observations, focusing on reading practices through the use of supplementary materials. The results indicate that the teachers promoted living situations of reading strategies in order to develop skills of reading comprehension, although the activities were not properly planned.

Keywords: complementary collection; reading strategies; reading comprehension; teaching resources; literacy.

A política nacional de ampliação do ensino fundamental (EF) para nove anos, no qual foram incluídas as crianças de seis anos, teve como objetivo investir na formação de leitores. Para tal, criaram-se espaços voltados à leitura em que o professor desempenha o papel de mediador ${ }^{1} \mathrm{e}$ implantou-se, em 2010, o Programa Nacional do Livro Didático (PNLD) Acervos Complementares, do Ministério da Educação (MEC), destinado às salas do $1^{\circ}$ e $2^{\circ}$ anos do EF da rede pública.

Essa iniciativa tem como objetivos a ampliação do universo cultural dos alunos nas diferentes áreas de conhecimento e o aumento das práticas de letramento no ambiente escolar. Foram selecionadas 150 obras de áreas diversas do conhecimento, distribuídas em 5 acervos com 30 livros cada um. A composição dos acervos foi feita de modo a garantir a presença de obras de distintos componentes curriculares, de temáticas variadas, de diferentes tamanhos e de variados níveis de leitura exigidos aos alunos. Os acervos seguiram à publicação do documento Acervos complementares: as áreas do conhecimento nos dois primeiros anos do ensino fundamental ${ }^{2}$ (Brasil, 2009), que se propõe a orientar o uso dessas obras nas salas de aulas.

Por meio dessas obras, o professor pode explorar diversos conteúdos curriculares e temáticas, favorecendo o aprendizado da leitura por meio de atividades em que as crianças vivenciem as mais variadas estratégias de leitura. Entre as contribuições, o referido programa se propõe a: permitir que as crianças, de forma lúdica, ampliem seus conhecimentos acerca dos diversos componentes curriculares; possibilitar a reflexão sobre os conhecimentos do sistema de escrita alfabética (SEA) por meio de textos curtos e atrativos; e contribuir para o desenvolvimento de habilidades de compreensão textual por meio de situações de leitura compartilhada.

\footnotetext{
${ }^{1}$ Utilizamos o termo professor mediador na perspectiva de Vygotsky (1998), segundo a qual a interação entre o professor e o aluno, bem como entre os alunos, contribui para a internalização do conhecimento. Em relação à mediação docente, destacamos que Vygotsky aponta que esta precisa ser planejada e ter intencionalidade educativa.

2 Doravante denominado "Manual do PNLD - Acervos Complementares". Os acervos complementares do PNLD foram implantados nas escolas brasileiras no ano de 2010, porém, a data de publicação do Manual é de 2009 .
} 
Embora sejam reconhecidas essas possibilidades, concordamos com Brandão e Rosa (2010) quando destacam que, apesar de haver na escola recursos de qualidade destinados à leitura, "persiste um grande número de alunos com dificuldade de entender o que leem, mesmo quando já estão em etapas mais avançadas de apropriação do sistema de escrita alfabético" (p. 108). Nesse sentido, este artigo apresenta uma reflexão sobre o ensino da leitura na alfabetização e sobre suas implicações para a formação do leitor; destacamos, ainda, a relevância dos acervos complementares enquanto recurso didático que pode ampliar o letramento das crianças em fase de alfabetização.

\section{Ensino da leitura na alfabetização: implicações para a formação do leitor}

Durante muito tempo o conceito de alfabetização foi definido como o ensino das habilidades de codificação e decodificação. A partir da década de 1980, começou a ser evidenciado que essas habilidades não eram suficientes para os sujeitos reconhecerem as funções e os usos da língua em diversas situações. Santos (2002) destaca que, na década de 1980, alguns trabalhos das áreas da Linguística e da Psicolinguística questionaram a noção de ensino-aprendizagem de língua escrita. Da concepção de língua apenas como código, a linguagem passou a ser compreendida como um processo de interlocução. Nessa perspectiva, "a língua é entendida enquanto produto da atividade constitutiva da linguagem, ou seja, ela se constitui na própria interação entre os indivíduos" (p. 31). A língua, portanto, passa a ser vista como enunciação, discurso, e não apenas como comunicação; assim, essa concepção de linguagem altera, consequentemente, a perspectiva de ensino da leitura na alfabetização.

Desde então, foi dada maior importância aos usos e às funções da língua nos contextos escolares por meio do envolvimento das crianças em práticas de leitura e de escrita significativas. O conceito de alfabetização passou, nesse sentido, a ser vinculado ao fenômeno do letramento (Soares, 2003). Concordamos com a afirmação de Soares (2003) de que alfabetização e letramento são duas ações distintas, porém inseparáveis, de modo que se alfabetiza letrando. Sob essa perspectiva, a criança torna-se alfabetizada e letrada ao mesmo tempo, configurando-se o professor como mediador na formação desses leitores e produtores de textos nas turmas de alfabetização.

Nesse sentido, Colomer e Camps (2002) afirmam que uma das tarefas dos professores no contexto escolar é ajudar os alunos a desenvolverem habilidades voltadas à interpretação da língua escrita. Assim, para que isso ocorra, faz-se necessário, de um lado, que a decifração não seja considerada como capacidade leitora, mas que esteja atrelada ao conjunto de habilidades necessárias para se entender um texto; e, de outro, que o ensino da leitura, enquanto forma de interpretação da realidade, estenda-se a todo o currículo escolar. 
Em consonância com essa nova perspectiva, Solé (1998) defende que ler é um processo de interação entre leitor/texto/autor e que nessa interação a construção do significado do texto envolve não só o próprio texto, mas os conhecimentos prévios do leitor e os objetivos pretendidos por ele. Segundo a referida autora, são os nossos objetivos e finalidades de leitura que guiam as interpretações que damos aos textos; dessa forma, quando sujeitos distintos leem o mesmo texto com intenções diferentes, podem extrair informações divergentes dessa leitura. Para que possamos compreender o que estamos lendo, mobilizamos estratégias de leitura definidas por Solé como "processos cognitivos e metacognitivos complexos, que exigem de quem lê a habilidade de pensar e planejar durante a leitura" (1998, p. 69-70).

Entre as estratégias de leitura definidas por Solé (1998), algumas são consideradas principais por Brandão e Leal (2005), a saber: traçar objetivos para a leitura; selecionar informações do texto; ativar conhecimentos prévios; antecipar sentidos no texto; elaborar inferências; avaliar e controlar a compreensão do texto. Segundo Brandão (2006), essas estratégias contribuem para o desenvolvimento da compreensão leitora, pois "[...] o leitor deve ir fazendo uma complexa triagem entre o que constitui detalhes que podem ser esquecidos e o que deve guardar em sua memória, para que possa construir o texto como um todo coerente" (p. 65). No que se refere ao ensino dessas estratégias, destacam ainda que a delimitação de objetivos claros e a intencionalidade do professor precisam ser estabelecidas.

Além disso, Kleiman (1998) destaca que, quando lemos um texto, seja ele qual for, estamos colocando em ação nossos valores, crenças e atitudes. Nessa perspectiva, essa autora destaca que, para ajudar o aluno a apreender o significado de um texto, é preciso que haja interação entre o professor e o aluno, pois é nesse momento que o leitor mais inexperiente compreende o texto. Nesse sentido, o papel do docente não é apenas colaborar para as crianças construírem o significado do texto; é preciso também que o professor entenda como os alunos fazem para chegar até essa compreensão. Para isso, de acordo com Leal e Melo (2006), no planejamento do ensino da leitura, o professor deve estabelecer finalidades variadas no intuito de atender a diferentes objetivos didáticos e de desenvolver estratégias de leitura diversificadas.

A pesquisa de Brandão e Rosa (2006) confirma que muitos dos conhecimentos e das habilidades para a leitura e a produção de texto podem ser desenvolvidos mesmo antes de os alunos dominarem a escrita alfabética. Para isso, as crianças devem ser levadas a refletir sobre as finalidades e as funções sociais que variados textos exercem na sociedade. Segundo as autoras, a leitura diária de textos diversos e o diálogo entre o professor e as crianças sobre esses textos lidos "são elementos fundamentais para que estas se apropriem de estratégias de compreensão que mais tarde poderão ser aplicadas quando elas estiverem lendo, de forma independente, os textos de sua escolha" (p. 52). 
Compreendemos, porém, que diversas ações devem ser levadas em conta pelo professor para que o processo de construção de sentidos na leitura se efetive. Entre essas ações, a escolha dos recursos a serem usados para a leitura constitui um elemento imprescindível. A pesquisa de Paiva (2010) demonstrou a importância da divulgação dos catálogos editoriais na escolha, para uso em contexto escolar, dos livros do PNLD - Acervos Complementares. Os resultados indicaram que $72 \%$ dos professores que participaram do estudo afirmaram a importância do uso do catálogo para atualização e escolha dos recursos didáticos nas escolas; entre esses professores, muitos aproveitaram as orientações presentes nas atividades indicadas para o uso dos recursos expostos nos catálogos. Além disso, os dados apontaram que, muitas vezes, as obras complementares do PNLD são desconhecidas devido à falta de divulgação de seus objetivos dentro da política de formação de leitores.

\section{Relato de pesquisa: obras do PNLD - Acervos Complementares- concepções sobre o uso e a vivência das estratégias de leitura pelas professoras alfabetizadoras}

A pesquisa teve um enfoque qualitativo (Lüdke; André, 2001) e investigou as concepções dos professores e o uso das obras do PNLD Acervos Complementares visando ao aprendizado da leitura nas turmas de $1^{\circ}$ e $2^{\circ}$ ano do EF. Buscamos responder às seguintes questões: quais as orientações para o ensino da leitura presentes no Manual dessas obras? O que pensam as professoras sobre as possibilidades de uso dessas obras para o ensino da leitura? As professoras promovem atividades em que as crianças vivenciam estratégias de leitura por meio da exploração dessas obras?

O campo escolhido para realizar a investigação foi uma rede municipal de ensino de Pernambuco pelo seu histórico de formações baseadas nas reflexões didáticas e pedagógicas sobre o uso das obras do PNLD - Acervos Complementares. Por meio de questionários aplicados, em toda a rede, às professoras de $1^{\circ}$ e $2^{\circ}$ ano do $\mathrm{EF}$, selecionamos duas, que atenderam aos critérios de: disponibilidade; assiduidade nas formações mencionadas; experiência de mais de 20 anos na alfabetização; formação em pedagogia há mais de 20 anos; e prática diária pautada pela leitura das obras dos acervos complementares. Das professoras selecionadas, uma lecionava no $1^{\circ}$ ano do EF e a outra no $2^{\circ}$ ano do EF, ambas na mesma escola.

Como procedimento de coleta dos dados, utilizamos três instrumentos (Lüdke; André, 2001): (1) análise documental, a fim de identificarmos as orientações para o ensino da leitura presentes no Manual do PNLD - Acervos Complementares, já que este é um documento que se propõe a orientar os professores quanto ao uso das obras; (2) entrevistas semiestruturadas com as professoras, para verificarmos as concepções que estas têm sobre 
as referidas obras; e (3) observações de quatro aulas de cada professora, para analisarmos em que medida as estratégias de leitura eram vivenciadas no uso das obras em turmas de alfabetização. As aulas observadas foram audiogravadas e também foram feitas anotações no diário de campo.

Como procedimentos de análise, utilizamos técnicas metodológicas da análise de conteúdo por meio de processos de descrição, de inferência e de interpretação (Bardin, 2007). Os resultados das análises foram agrupados em três tópicos, apresentados a seguir, no intuito de responder às questões elencadas anteriormente.

Orientações para o ensino da leitura nos anos iniciais presentes no Manual do PNLD - Acervos Complementares

A análise das orientações para o ensino da leitura presentes no Manual do PNLD - Acervos Complementares indica que o referido Manual convida o professor a conhecer as diversas obras paradidáticas que compõem os acervos ao mostrar a importância de cada componente curricular para as séries iniciais do EF. O referido documento está divido em três partes. Na primeira, há uma breve introdução que mostra as mudanças trazidas pelo EF de nove anos para o contexto escolar, além de apresentar ao professor resultados de pesquisas que confirmam a importância de um ambiente favorável ao letramento, com recursos atrativos para a formação leitora dos alunos. Na segunda parte, são apresentadas algumas competências e habilidades para os anos iniciais do EF, bem como os eixos temáticos que podem ser trabalhados a partir das obras dos acervos em diferentes componentes curriculares. Para cada área do conhecimento são indicados objetivos relativos ao ensino e à aprendizagem, nos quais se destaca a importância da compreensão de textos a partir das leituras dos livros pelos professores e pelos alunos.

Ao tratar das obras na área curricular de Língua Portuguesa, o Manual destaca a importância da vivência, desde os anos iniciais do EF, das estratégias de leitura e os tipos de reflexões e situações de aprendizagens em que essas estratégias podem ser vivenciadas pelas crianças. Entre essas situações, destacamos as orientações quanto ao desenvolvimento de habilidades de compreensão textual e de apropriação do sistema de escrita alfabética (SEA) por meio da reflexão sobre: os nomes das letras; as correspondências grafofônicas; as rimas e aliterações presentes nos mais variados gêneros textuais, como parlendas, trava-línguas, poemas, histórias etc. Além disso, há indicação de outras habilidades que podem ser desenvolvidas por meio da reflexão sobre os recursos linguísticos e sobre o significado de palavras ou de expressões.

Na última parte do documento, verificamos uma espécie de catálogo com as capas das 150 obras selecionadas para compor os acervos e uma breve descrição do que cada obra apresenta. Essa descrição serve, assim, como subsídio para o professor na escolha do livro que poderá utilizar no desenvolvimento de determinadas competências e habilidades. 
Concepções das professoras sobre as possibilidades de uso das obras do PNLD - Acervos Complementares para o ensino da leitura na alfabetização

A análise das concepções das professoras sobre as possibilidades de uso das obras do PNLD - Acervos Complementares para o ensino da leitura indicou que, em relação aos recursos utilizados para o ensino da leitura e da escrita, ambas as professoras reconhecem a importância da diversidade de recursos didáticos nas séries iniciais e utilizam as referidas obras em suas aulas. Além disso, consideram a riqueza e a qualidade dos materiais, a diversidade das temáticas e a importância dos livros nos anos iniciais do $\mathrm{EF}$, conforme ilustram os depoimentos a seguir:

[...] Quem vai aprender a ler e a escrever tem que ter muita leitura inicialmente. E, no mais, a gente utiliza jogos. A gente já usa aqui na escola, né? [referindo-se às obras complementares]. Assim... eu meio que comecei a usar sem saber realmente que fazia parte de um programa. Mas aí depois ouvi comentários sobre eles. A gente ficou meio curiosa, assim, e foi investigar. Aí, a gente começou a usar eles com outro olhar, né? Porque primeiro a gente usa sem saber que faz parte de um programa, tal... Aí quando a gente começa a perceber, aí a gente começa a ver com outro olhar, né? (Professora A).

[Uso] revistas, jornais, os livros, né? Poemas, poesias e livros paradidáticos. Uso muito trava-línguas. Eu gosto muito de parlendas, porque são menores e a questão da rima. E muito bom a gente trabalhar; eles se apropriam mais. Em relação aos livrinhos [referindo-se às obras complementares], também uso para algumas atividades de apropriação da escrita. (Professora B).

As duas professoras também enfatizam que, em suas rotinas diárias, dispõem de um momento para leitura deleite com livros de diversos gêneros textuais, o que faz ampliar o repertório de leituras de seus alunos. Destacamos, contudo, que, apesar de as obras virem acompanhadas pelo Manual do PNLD - Acervos Complementares, as professoras sujeitos dessa investigação desconhecem os objetivos subjacentes ao uso desses recursos didáticos. Isso ficou evidente quando perguntamos à Professora B se ela utilizou o Manual que acompanhava os acervos para conhecer melhor as obras e para subsidiar as suas intervenções didáticas. A docente nos relatou que ainda não tinha tido tempo de olhar o material com cuidado. Ressaltamos, assim, a importância da divulgação dos manuais disponibilizados pelo MEC a fim de se qualificar o uso dessas obras, como salientou Paiva (2010). Além disso, destacamos que as políticas de formação de leitores têm sido implantadas nas escolas sem estarem atreladas a atividades de formação dos professores que utilizarão, em sala de aula, os acervos disponibilizados.

Em relação às formas de uso das obras e temáticas já abordadas, ambas as professoras ressaltam que, por se tratar de gêneros textuais e de áreas do conhecimento diversas, as obras permitem várias formas de uso. A Professora A destaca que as obras são pertinentes para o trabalho nos anos iniciais do EF pelo fato de alguns livros apresentarem, especificamente, 
o trabalho com as letras, as rimas e as aliterações. Segundo ela, seria importante apresentar aos alunos, ainda no período de alfabetização, recursos que viabilizem não somente a ampliação do letramento, mas também a reflexão sobre a escrita, por meio das rimas e das aliterações - o que possibilita avanços na apropriação do SEA. Além disso, a docente apresenta suas impressões sobre a riqueza gráfica do material e sobre a diversidade temática encontrada nas obras.

Em relação a esse último aspecto, a Professora B enfatiza algumas temáticas que já tinham sido vivenciadas em suas aulas, a exemplo da obra Kaka Darebuque. Segundo ela, esse livro foi usado "na época do dia dos índios. [...] A gente não olhou só a questão do índio, mas da arte, que a gente não tem Artes, né?". Verificamos no discurso dessa professora que, mesmo sem observar as orientações contidas no Manual, ela identifica o caráter interdisciplinar das obras do PNLD - Acervo Complementares.

Quanto a possibilidades de ensino da leitura a partir das obras, as professoras A e B apresentam, por um lado, aproximações e, por outro, distanciamentos em relação às situações didáticas que dizem promover na aula, conforme verificamos nos depoimentos a seguir:

\begin{abstract}
Rapaz, a leitura desses livros é muito gostosa, né? Primeiro, é como eu te disse: nessa fase eles precisam muito de ouvir. Ouvir a história, se encantar com a história, porque, quando eles começam a perceber que podem escrever histórias deles, aí eles entendem melhor. Aí é que eles se interessam para aprender a ler e escrever, se interessam para ler, e só depois querem ler outras coisas porque já podem compreender tudinho. (Professora A).
\end{abstract}

Estou sempre lendo, trazendo novidades, livros novos, cada dia um livro novo; aí eles já esperam, né? Para ver a capa, para ver a cor, para ver se tem desenhos, as letras, para ver o tamanho. É grosso ou fino? É grande ou pequeno? Isso aí incentiva, né? Já vai incentivando eles a olhar tudo, a ver o livro como todo, mesmo sem saber ler [as crianças]. Eu leio também essa partezinha [sinopse] e pergunto o que tem aqui, né? Peço um resumozinho e pergunto outras coisas sobre o que foi lido. (Professora B).

Apesar de destacarem a importância de ler para os alunos desde cedo como incentivo ao prazer pela leitura, a Professora A indica que o trabalho com foco na compreensão só deve ser iniciado após a apropriação da escrita pela criança, ao passo que a Professora B destaca que busca desenvolver a atividade de leitura de forma significativa para que a criança já compreenda o texto mesmo não estando alfabetizada. Ressaltamos, portanto, que essas situações de leitura do livro precisariam ser planejadas pelo professor no intuito de atender a objetivos claros e definidos no que se refere à vivência de estratégias de leitura.

Em relação ao planejamento das atividades de leitura com as obras, em vários momentos, identificamos a ausência de intencionalidade para a realização dessas atividades, apesar de, muitas vezes, elas anunciarem promover algumas situações que tinham como foco a leitura ao longo da aula, conforme vemos no depoimento da Professora A. 
Rápido como um gafanhoto, posso falar sobre esse, que eu planejei com essa turma do ano 1. Primeiro eu fiz a leitura deleite, aí, no outro dia, eu peguei ele para trabalhar com a leitura. Eu gosto muito de trabalhar com esses textos que eles já conhecem. No dia em que eu fui trabalhar leitura, primeiro a gente leu e releu várias vezes. E aí eu pedi para cada aluna fazer o seu, né? Assim: você é como qual bicho, você gostaria de ser como qual bicho? Aí, cada um fez o seu e a gente escreveu a frase de cada um, fulaninha tal..., aí escreveu, fez o cartaz com a escrita. E, a partir desse cartaz, a gente fez um trabalho com leitura, de um a um. Aí eu pedia para Alisson ler o que era de Jussara, tinha que encontrar lá no cartaz qual foi a frase de Jussara, né? Então isso é um exercício de leitura que é muito interessante para eles, que estão começando agora. Então essa atividade foi maravilhosa e foi com esse livro aqui: Rápido como um gafanhoto. (Professora A).

Nesse trecho, percebemos que a docente não menciona uma intencionalidade em proporcionar a vivência das estratégias de leitura pelas crianças. Ao perguntarmos se em suas aulas ela aborda algumas das estratégias de leitura que viabilizam a compreensão textual, percebemos que a docente desconhece o termo estratégias de leitura ao confundi-lo com estratégia didática. $\mathrm{O}$ trecho a seguir é ilustrativo:

O livro Jonas e as cores é um livro que a gente pode usar uma mesma estratégia a semana inteira. Para ler na sexta-feira, por exemplo: "Jonas mandou dizer que vem visitar vocês", entendeu? A gente diz isso na segunda-feira, na terça-feira a gente relembra aos meninos: "vocês lembram quem eu disse que viria visitar vocês?" Alguém vai lembrar; se não lembrar, você diz: "foi Jonas, Jonas disse que viria visitar vocês". Então vamos esperar, será que ele vem hoje ainda? E os alunos vão passar a semana toda, com essa incógnita, com essa pergunta, de quem é Jonas? (Professora A).

Observamos que o significado dado à palavra estratégia pela docente estaria relacionado à forma com que desperta a curiosidade das crianças para a leitura do livro Jonas e as cores. Diante de sua resposta, reformulamos a pergunta e questionamos se ela faz questões de antecipações e verificação de hipóteses antes, durante e depois da leitura. A esse novo questionamento, a professora responde:

Antes a gente pode fazer aquelas perguntas que a gente faz sempre, né? Como é que se escreve Jonas, por exemplo? Eles já conhecem as letras, né? "Com J, não é, professora?" E durante... do mesmo jeito. A gente deve dar atenção para aquelas palavras-chave que a gente quer destacar, né? (Professora A).

Novamente, percebemos que a docente confunde o trabalho das estratégias de leitura com os encaminhamentos dados por ela para as atividades de apropriação do SEA. Em outro momento da entrevista, a Professora A menciona que tinha finalidades para a leitura, no entanto, não explicita tais finalidades e nem deixa claro por que seriam importantes, conforme se ilustra no seu depoimento:

[...] porque, se você lê sempre e não tem uma finalidade, o aluno começa a perceber que a leitura não serve para nada. Quando você lê e está 
sempre voltando àquela leitura, para as situações de sala de aula, o aluno vai perceber que a leitura é importante. (Professora A).

Da mesma forma, a Professora B, ao falar do planejamento das atividades de leitura com as obras, centra-se na questão da decodificação das palavras e, aparentemente, não menciona preocupação com a questão da compreensão textual.

\begin{abstract}
Assim, vamos dizer assim: um texto que tenha rimas, pegava aquela partezinha ali e tomava a leitura individualmente, também fazia isso. E às vezes assim: através de tiras, pegava aquela partezinha e dizia "venha cá, vamos ler aqui". Ou então assim: se eles já leram esse livro hoje, aí no outro dia eu pegava e chamava, né? "Você vai ler essa parte aqui"; aí eles liam algumas palavras, no dia a dia mesmo, depois que eu contava, né? Recontava, eles liam da forma deles, eles iriam olhar, né? E quem soubesse ler lia, né? E os que não, eles iriam lembrar o que eu tinha lido ali. (Professora B)
\end{abstract}

Diante de sua resposta, questionamos sobre quais estratégias de leitura poderiam ser desenvolvidas a partir dos livros dos acervos. A professora B demonstra desconhecer o que seriam estratégias de leitura. Então, reformulamos a pergunta e indagamos se ela fazia antecipações e verificação de hipóteses antes, durante e depois da leitura. Ao nos responder, a professora B afirma que fez um levantamento das hipóteses sobre o título da obra e que buscou levantar os conhecimentos de mundo dos seus alunos. Além disso, a docente procura, durante a leitura, fazer antecipações e resgatar as hipóteses das crianças sobre o texto por meio de questões. Apresentamos a seguir um trecho da fala em que ela exemplifica seu trabalho com a estratégia de antecipação da leitura.

A questão do título: sabem o que são mamíferos? Se eu falo "mamíferos", eles teriam que saber o que seriam, né? Deixa eu ver um que eu trabalhei... pronto: Rápido como um gafanhoto. Se o título diz isso, Rápido como um gafanhoto, vai falar de quê? Entendesse? Se é rápido como um gafanhoto, eu não posso falar de uma preguiça; vai falar de quem? (Professora B).

Em relação ao acesso às obras pelas crianças, identificamos que esses livros não estão disponíveis para os alunos, já que não ficam permanentemente nas salas de aula, segundo os depoimentos de ambas as professoras. A professora A relata que tem um "cantinho da leitura", mas que nem todas as obras do acervo ficam em sua sala, e ainda afirma que esses livros servem como recurso didático para os alunos do $1^{\circ}$ ao $5^{\circ}$ ano da escola. A professora B informa que os alunos de sua turma não têm acesso a esse material de forma autônoma, pois podem rasgá-lo. Verificamos, portanto, a não observação das orientações presentes no Manual dos Acervos Complementares, o qual indica que os livros que compõem esses acervos devem ficar nas salas de $1^{\circ}$ e $2^{\circ}$ ano do $\mathrm{EF}$, do mesmo modo que apresenta como maior compromisso do programa o estímulo à curiosidade do aluno.

Observamos, portanto, a dicotomia escolar que Colomer e Camps (2002) apresentam entre "aprender a ler e ler para aprender" na concepção de 
ambas as professoras sobre as possibilidades de uso das obras para o ensino da leitura. Nos depoimentos analisados, ficou evidente que as professoras centram a aprendizagem, nos primeiros anos do EF, na aquisição da escrita e remanejam, para os anos seguintes, a atividade de inserção em práticas reais de leitura - apesar de destacarem a importância da leitura das obras dos acervos complementares do PNLD nas suas aulas. Os resultados apresentados indicam a importância de a formação docente dar condições ao professor de refletir sobre os recursos didáticos disponibilizados pelo MEC enquanto possibilidades para o ensino da leitura na alfabetização, de forma aprofundada, significativa e contextualizada.

Vivência das estratégias de leitura por meio da exploração das obras do PNLD - Acervos Complementares: planejar é preciso?

Neste tópico, buscamos analisar se as professoras promovem atividades em que as crianças vivenciam estratégias de leitura, por meio da exploração das obras do PNLD - Acervos Complementares, e como isso ocorreu. Inicialmente, identificamos as obras utilizadas e os respectivos componentes curriculares trabalhados pelas docentes em todas as aulas.

\section{Quadro 1 - Livros Usados pelas Duas Professoras}

\begin{tabular}{|c|c|c|c|c|c|}
\hline \multicolumn{6}{|c|}{ PROFESSORA A } \\
\hline $\begin{array}{l}\text { Livros dos Acervos } \\
\text { Complementares }\end{array}$ & $\begin{array}{l}\text { Componente } \\
\text { Curricular }\end{array}$ & $1^{\mathrm{a}}$ Aula & $2^{a}$ Aula & $3^{a}$ Aula & $4^{a}$ Aula \\
\hline As cores & Artes & $\mathrm{X}$ & & & \\
\hline Isto não é & Artes & & $\mathrm{X}$ & & \\
\hline Rápido como um gafanhoto & Ciências & & & $\mathrm{X}$ & $\mathrm{X}$ \\
\hline Os animais & Ciências & & & & $\mathrm{X}$ \\
\hline \multicolumn{6}{|c|}{ PROFESSORA B } \\
\hline $\begin{array}{l}\text { Livros dos Acervos } \\
\text { Complementares }\end{array}$ & $\begin{array}{l}\text { Componente } \\
\text { Curricular }\end{array}$ & $1^{a}$ Aula & $2^{\mathrm{a}}$ Aula & $3^{a}$ Aula & $\begin{array}{c}4^{\mathrm{a}} \\
\text { Aula }^{(1)}\end{array}$ \\
\hline Alfabeto de histórias & Língua Portuguesa & & $\mathrm{X}$ & & \\
\hline Os dez amigos & Matemática & & & $\mathrm{X}$ & $\mathrm{X}$ \\
\hline Rápido como um gafanhoto & Ciências & $\mathrm{X}$ & $\mathrm{X}$ & & \\
\hline
\end{tabular}

Nota: ${ }^{(1)}$ Obs.: Além destes, na quarta aula a docente fez a leitura do livro A casa sonolenta, que não fazia parte dos acervos complementares em 2010.

Em seguida, categorizamos as estratégias de leitura vivenciadas pelas professoras e verificamos a qualidade da interação desenvolvida durante a atividade com as crianças, conforme apresentaremos a seguir.

A fim de motivar os alunos para a leitura, a Professora A usou algumas estratégias. Em alguns momentos, ela instiga os alunos a se envolverem na atividade por meio de uma breve preparação para a leitura, na qual destaca a temática da obra e a relaciona a experiências vivenciadas pelas crianças. Essa professora também usa constantemente obras em que há destaque 
para as imagens, tais como os livros As cores e Isto não é. O primeiro é um livro de imagens que apresenta uma seleção de fotografias e o segundo é um livro que possui texto verbal e imagens atrativas. Por fim, a professora A explora a brincadeira enquanto elemento motivacional para a leitura da obra. Quando ela usa o livro Rápido como um gafanhoto, brinca com as comparações que há na obra sobre as qualidades de cada ser humano e cita os nomes dos alunos na brincadeira. Em seguida, propõe que todos pensem nos animais que mais gostam e solicita que escrevam os nomes desses animais no caderno. Por fim, a docente lista no quadro os nomes dos animais citados pelos alunos, faz uma roda de leitura no pátio e cria rimas entre os nomes das crianças e os dos animais escolhidos.

Em relação à motivação para a leitura nas aulas da professora B, destacamos que a docente tenta fazer antecipações no intuito de estimular os alunos a analisarem as imagens da capa e o título do livro, conforme apresentamos a seguir.

P: Leitura deleite. E o que é que eu tenho aqui na minha mão?

A: Livro.

P: Ele é fino, grosso?

A: Fino.

P: Ele é grande ou pequeno?

A: Grande.

P: Esse livro tem apenas uma cor ou ele é colorido?

A: Colorido.

P: Na capa do livro tem desenhos ou só palavras?

A: Tem desenhos e palavras.

P: Essas palavras querem dizer o quê?

A: Palavras...

P: O título do livro, não é?

A: Gafanhoto.

P: "Rápido como gafanhoto". Os autores são: Audrey Wood. Posso começar?

A: Pode.

(1ª observação, Professora B).

Apesar da tentativa de motivar as crianças para a leitura, destacamos que a professora B poderia ter elaborado questões mais reflexivas sobre a obra a ser lida em vez de se deter em questões relativas apenas à descrição da imagem da capa. Segundo Vieira e Fernandes (2010), os livros com imagens atrativas viabilizam o letramento das crianças nas séries iniciais, pois contemplam o desenvolvimento da linguagem oral e a apreciação da linguagem visual. Contudo, para que a atividade com essas imagens contribua para a compreensão leitora, o professor precisa planejar as atividades trabalhadas em sala de aula a fim de explorar as imagens e desenvolver a leitura não verbal.

Com relação ao levantamento dos conhecimentos prévios dos alunos, observamos essa atividade de resgate em três aulas da professora A. Em uma delas, durante a leitura do livro As cores, a docente, a cada página, pergunta se as crianças identificam a imagem em destaque com base em suas experiências anteriores. Em relação a esse aspecto, apenas na primeira aula da Professora B evidenciamos uma tentativa de resgatar esses 
conhecimentos das crianças quando a docente pede que eles identifiquem os animais apresentados no livro. Em ambas as turmas, verificamos que a vivência das crianças com a estratégia de leitura em destaque foi superficial e limitou-se apenas a uma atividade de reconhecimento de imagens seguida de uma atividade de escrita de palavras. Em nenhum momento essa atividade apresentou uma intencionalidade ou um aprofundamento quanto aos aspectos que seriam explorados para a compreensão do texto.

No que se refere ao levantamento de hipóteses antes, durante e depois da leitura, a Professora A, de modo geral, não cria situações em que as crianças possam vivenciar essa estratégia de leitura. Ao fazer a leitura do livro Os animais - que discute os direitos dos animais -, a referida professora realiza pausas e, ao ler cada parte da obra, faz perguntas para verificar se eles estão prestando atenção à leitura, porém, essas questões não demandam uma compreensão mais elaborada do texto. Em relação a esse aspecto investigado, a professora B incentiva, antes da leitura da obra, o posicionamento dos alunos sobre o que sabem da temática do texto e, após a leitura, conduz a atividade de interpretação oral: apresenta situações do dia a dia, comparando-as com o que o texto destaca. Na entrevista, ela afirmou que tem a intenção de resgatar os sentidos do texto lido por meio das perguntas.

Ao analisarmos se as professoras buscam problematizar o texto que está sendo lido, identificamos que as docentes não exploram esse tipo de estratégia de leitura em suas aulas. Da mesma forma, não proporcionam atividades em que as crianças vivenciem o levantamento de inferências a partir dos textos lidos. Como bem salienta Brandão e Leal (2005), a capacidade de elaborar inferências a partir de uma leitura é uma das habilidades mais complexas que o leitor desenvolve na tentativa de compreender um texto; essa habilidade, portanto, deve ser explorada desde os anos iniciais.

Quanto à localização de informações explícitas no texto, a professora A, em quase todas as aulas observadas, fez pausas ao longo da leitura e, por meio de perguntas, permitiu que os alunos identificassem as informações solicitadas. Na terceira aula, a professora A inicia a leitura do livro Os animais. Mesmo sem explorar o título nem as ilustrações da capa, durante a leitura, a docente vai indagando aos alunos as possíveis características dos animais já lidas por ela na obra. Da mesma forma, na atividade com o livro Os dez amigos, a professora B estimula a vivência dessa estratégia por parte das crianças, conforme ilustra o trecho a seguir.

P: O que aconteceu ontem, ontem? Ontem, o que aconteceu? Quando tia Márcia contou, ontem?

A: O livro de Ziraldo.

P: Pronto, o livro de Ziraldo; mas o que aconteceu na historinha de ontem?

A: Terminou com: os quatros eram presos.

P: Terminou com: os quatros eram presos; foi isso?

A: Igual à novela

P: Igual à novela. Eles começaram a contar como eles eram, contaram o nome deles. O que eles faziam? Mas só que hoje aconteceu o quê? Eles sumiram, foi? Ou apareceram mais? 
A: Apareceram mais.

P: Ah! Apareceram mais. E quem foi que apareceu?

A: Dedo mindinho, seu vizinho, maior de todos, tira bolo e cata piolho.

$$
\text { (4 } 4^{\mathrm{a}} \text { observação, professora B) }
$$

Kleiman (1998) destaca a importância de o professor verificar a compreensão do tex to lido e explorar suas informações explícitas, a fim de reconstruí-lo com as crianças. Entretanto, ao analisarmos o trecho da aula da professora $\mathrm{B}$, identificamos que ela não faz perguntas que proporcionem um resgate do texto propriamente dito; apenas destaca alguns fatos relatados, sem motivar as crianças a se posicionarem e a expressarem suas opiniões. Apesar disso, identificamos, em duas aulas, a preocupação dessa professora em proporcionar a apreensão dos sentidos do texto lido. O extrato de uma de suas aulas ilustra essa constatação:

P: Vejam só, na nossa família não tem um montão de gente?

A: Tem.

P: Tem pai, tem mãe, não é verdade? Tem irmão.

A: E.

P: Irrmãozinho, prima, avó, avô, não é assim?

A: E.

P: Na nossa casa, tem nosso pai, nossa mãe, o irmãozinho, ou a madrasta, ou o padrasto ou a vovó, ou o vovô, não é?

A: Ou a tia.

P: Eles podem fazer igual ao vilão que ia brigar?

A: Não.

P: Não, eles devem ficar um ajudando o outro; vai dar certo assim?

A: Vai.

P: Vão ser felizes?

A: Vão.

P: Como diz o ditado popular, "uma mão lava a outra", não é assim? Quando eu vou lavar minhas mãos, uma mão lava a outra, não é? A mesma coisa é em casa, não é, Kauã? Ajudar a mãe, o pai em casa, não é? Em casa, na nossa família, um pode ajudar o outro, não é verdade?

$$
\text { (4 } 4^{\mathrm{a}} \text { observação, professora B). }
$$

É notório que as professoras investigadas têm uma preocupação quanto à participação das crianças nos momentos de leitura, apesar de destacarmos que pouco investem na qualidade das perguntas de compreensão elaboradas. O maior investimento das professoras - principalmente da professora B - é na reflexão sobre o SEA, sobre as palavras e frases do texto após as atividades de leitura. Em todas as aulas, com base nas leituras realizadas e de forma indireta durante o momento de leitura, ambas as professoras refletem sobre a composição das palavras retiradas do texto. A professora B faz comparações entre as palavras quanto ao número de letras e de sílabas, quanto às rimas e às aliterações; realiza a atividade de bingo com as palavras do texto e promove a montagem e desmontagem de trechos dos textos lidos, entre outras atividades. Nos extratos de aula a seguir, destacamos algumas das atividades desenvolvidas por essa docente:

P: Eu distribuí para cada um de vocês uma frase do livro, tá? A gente vai colar aqui no glossário. Já leu? 
A: Já.

P: Quem está com o título? "Rápido como Gafanhoto"?

A: Eu.

P: Cole aqui. Mas tem outra pessoa que pegou "Sou rápido como um gafanhoto". Agora quem pegou "Sou lento como caracol"?

( (2a observação, professora B).

P: "C" de circo. "C" de camelo. Carolina, "A cabra calculou a posição correta do canhão para Cilo, o cão bala, cair certeiro no colchão. Caramba! Que cachorro corajoso!" As palavrinhas começaram com a letra?

A: "C".

P: Mas vamos ver as palavras com a letra "C". Lemos as palavras [...].

(2a observação, professora B).

Por fim, destacamos que, apesar de as professoras realizarem a leitura dos livros dos acervos complementares em suas aulas, as atividades de vivência das estratégias de leitura pelas crianças não têm intencionalidade educativa. Ressaltamos, portanto, que as docentes não planejam as questões que pretendem propor às crianças a partir da leitura das obras dos acervos complementares, pois as formulam improvisadamente na maioria das vezes. Mais uma vez, destacamos a importância da formação continuada de professores na condução do efetivo conhecimento do PNLD - Acervos Complementares e da vivência das estratégias de leitura por meio da exploração dessas obras. A troca de experiências entre os pares e a proposição de situações significativas podem ajudar os professores no planejamento do momento de mediação nessas atividades a fim de que essa interação seja qualificada.

\section{Considerações finais}

Considerando as discussões acerca da importância da leitura nos contextos de alfabetização para formação do leitor, investigamos como os professores estão utilizando os acervos complementares nas salas de aula do $1^{\circ}$ e $2^{\circ}$ anos do EF quanto ao aprendizado da leitura. Apesar dos limites de nossa pesquisa - por se tratar de um estudo exploratório com apenas dois sujeitos -, ressaltamos alguns pontos relevantes observados nos resultados. Detivemo-nos no uso dos acervos complementares por constituírem um programa que prevê a ampliação do letramento e dos conhecimentos dos alunos do $1^{\circ}$ e $2^{\circ}$ anos do EF por meio de variadas temáticas.

A análise do Manual do PNLD - Acervos Complementares indica que esse documento possibilita ao professor conhecer, de forma mais próxima, os diversos livros que compõem os acervos e que podem contribuir para a formação do leitor iniciante. O referido documento também sugere atividades e situações pedagógicas de uso das obras por meio das quais várias estratégias de leitura podem ser vivenciadas de forma qualitativa pelas crianças. 
Em relação às professoras da investigação, destacamos que, apesar de reconhecerem a importância das obras para o ensino da leitura em suas turmas e a contribuição destas para as atividades de reflexão sobre o SEA, as docentes desconheciam a existência do Manual. Além disso, a análise de suas práticas indica que foram proporcionados momentos de vivência das estratégias de leitura para as crianças, mesmo que estes não tenham sido planejados pelas docentes. Apesar da ausência de intencionalidade no ensino da leitura, destacamos que as professoras buscam realizar atividades de compreensão leitora nas turmas com crianças ainda não alfabetizadas, o que representa a intenção de desenvolver uma alfabetização na perspectiva do letramento.

Por fim, nossos resultados, por um lado, apontam para a importância de uma maior divulgação e da discussão sobre os recursos disponibilizados pelo MEC para as redes de ensino e, por outro, indicam que muitas vezes as políticas educacionais são introduzidas nas escolas sem que ocorra em paralelo a formação de professores a fim de que as desenvolvam com qualidade. Além disso, ressaltamos a importância de as redes de ensino investirem, de forma mais qualitativa, na formação dos professores concernente aos aspectos didáticos e pedagógicos para o ensino da leitura e da compreensão leitora nos anos iniciais do EF.

\section{Referências bibliográficas}

BARDIN, L. Análise de conteúdo. Lisboa: Ed. 70, 2007.

BRANDÃO, A. C. P.; LEAL, T. F. Em busca da construção de sentidos: o trabalho de leitura e produção de textos na alfabetização. In: BRANDÃO, A. C. P.; ROSA, E. C. de S. Leitura e produção de textos na alfabetização. Belo Horizonte: Autêntica, 2005. p. 27-43.

BRANDÃO, A. C. P.; ROSA, E. C. A leitura de textos literários na sala de aula: é conversando que a gente se entende... In: PAIVA, A.; MACIEL, F.; COSSON, R. (Coord.). Literatura e formação de leitores no ensino fundamental. Brasília, DF: CEALE/SEB/MEC, 2010. p. 59-106. (Coleção explorando os sentidos, v. 20).

BRANDÃO, A. C. P. O ensino da compreensão e a formação do leitor: explorando as estratégias de leitura. In: SOUZA, I. P.; BARBOSA, M. L. F. F. Práticas de leitura no ensino fundamental. Belo Horizonte: Autêntica, 2006. p. 59-75. 
BRASIL. Ministério da Educação (MEC). Secretaria de Educação Básica (SEB). Acervos complementares: as áreas do conhecimento nos dois primeiros anos do ensino fundamental. Brasília, DF: MEC/SEB, 2009.

COLOMER, T.; CAMPS, A. Ensinar a ler, ensinar a compreender. Porto Alegre: Artmed, 2002.

KLEIMAN, A. Oficinas de leitura: teoria \& prática. Campinas, SP: Pontes, 1998.

LEAL. T. F.; MELO, K. Planejamento do ensino da leitura: a finalidade em primeiro lugar. In: SOUZA, I. P.; BARBOSA, M. L. F. F. Práticas de leitura no ensino fundamental. Belo Horizonte: Autêntica, 2006. p. 39-57.

LÜDKE, M.; ANDRÉ, M. Pesquisa em educação: abordagens qualitativas. 6. ed. São Paulo: EPU, 2001.

PAIVA, A. Catálogos de editoras e escolhas docentes no contexto escolar. In: PAIVA, A.; MACIEL, F.; COSSON, R. (Coord.). Literatura e formação de leitores no ensino fundamental. Brasília, DF: CEALE/SEB/ MEC, 2010. p. 171-182. (Coleção explorando os sentidos, v. 20).

SANTOS, C. F. A Formação em serviço do professor e as mudanças no ensino de língua portuguesa. Revista Educação Temática Digital, Campinas, SP, v. 3, n. 2, p. 27-37, jun., 2002.

SOARES, M. B. Letramento: um tema em três gêneros. 2. ed. Belo Horizonte: Autêntica, 2003.

SOLÉ, I. Estratégias de leitura. Tradução de Cláudia Schilling. 6. ed. Porto Alegre: Artmed, 1998.

VIEIRA, A. S.; FERNANDES, C. R. D. O acervo das bibliotecas escolares e suas possibilidades. In: PAIVA, A.; MACIEL, F.; COSSON, R. (Coord.). Literatura e formação de leitores no ensino fundamental. Brasília, DF: CEALE/SEB/MEC, 2010. p. 107-126. (Coleção explorando os sentidos, v. 20).

VYGOTSKY, L. S. A formação social da mente: o desenvolvimento dos processos psicológicos superiores. Tradução de José Cipolla Neto, Luís Silveira Menna Barreto e Solange Castro Afeche. 6. ed. São Paulo: Martins Fontes, 1998. 
Rielda Karyna de Albuquerque, mestranda em Educação pela Universidade Federal de Pernambuco (UFPE), é professora da Rede Municipal de Ensino de Jaboatão dos Guararapes. Formadora e membro do Centro de Estudos em Educação e Linguagem (CEEL) da UFPE, Recife, Pernambuco, Brasil.

E-mail: rieldalbuquerque@gmail.com

Magna do Carmo Silva Cruz, doutora em Educação pela Universidade Federal de Pernambuco (UFPE), é professora de Avaliação da Aprendizagem da Universidade Federal de Pernambuco (UFPE) e coordenadora do Centro de Estudos em Educação e Linguagem (CEEL) da UFPE, Recife, Pernambuco, Brasil.

E-mail: magna_csc@yahoo.com.br

Recebido em 14 de junho de 2014.

Solicitação de correções em 4 de novembro de 2014.

Aprovado em 24 de novembro de 2014. 